\title{
Stage IV Adult Diffuse Small Cleaved Cell Lymphoma
}

National Cancer Institute

\section{Source}

National Cancer Institute. Stage IV Adult Diffuse Small Cleaved Cell Lymphoma. NCI

Thesaurus. Code C8146.

Stage IV: Disseminated (multifocal) involvement of one or more extralymphatic sites with or without associated lymph node involvement or isolated extralymphatic organ involvement with distant (nonregional) nodal involvement. (PDQ) 